\title{
State of Entrepreneurship Attitude and Intention among Malaysian Youngsters
}

\author{
Hasliza Hassan \\ Faculty of Management, Multimedia University, Cyberjaya, Selangor, Malaysia \\ hasliza.hassan@mmu.edu.my / liza.hassan@yahoo.com*
}

\begin{abstract}
Abu Bakar Sade
Putra Business School, Universiti Putra Malaysia, Serdang, Selangor, Malaysia abubakar.sade@putrabs.edu.my

Melissa Wendy Migin

Faculty of Management, Multimedia University, Cyberjaya, Selangor, Malaysia melissa.migin@mmu.edu.my
\end{abstract}

\begin{abstract}
Entrepreneurship among the youngsters in Malaysia is expected to spice-up the existing socioeconomic development momentum. Many initiatives have been introduced to spur the entrepreneurship spirit among the youngsters. This research focuses on the attitude and intention of youngsters in becoming entrepreneurs. Cross-sectional research was conducted to determine the attitude and intention of the youngsters to be an entrepreneur using a survey questionnaire. Descriptive and correlation analyses were conducted using 425 data that were collected from students who have taken the entrepreneurship course at the Multimedia University, Cyberjaya, Selangor, Malaysia. It is found that the youngsters have a positive attitude and intention towards entrepreneurship. Further findings also highlight that the positive attitude influences the positive intention for the youngsters to venture into entrepreneurship. Shaping the attitude and intention through the basic entrepreneurship knowledge that can be learned from formal education is expected to become an entrepreneurial engine to drive the economic development for the nation.
\end{abstract}

Keywords: Attitude; Entrepreneur; Entrepreneurship; Intention; Youngsters

\section{Introduction}

Entrepreneurship is an act of creating a business to earn a profit (Ferreira, 2018). Hence, entrepreneurship is a very common word that is used to enhance the socioeconomic level because the activities do not just benefit a specific individual but the local community. At present, there is no standardized definition concerning the term entrepreneurship since the definition is continuously being redefined to meet the continuous changes from the modern industrial revolution. In general, entrepreneurship refers to those people who are willing to take a risk by venturing into a new business. Most developing countries, including Malaysia, emphasize entrepreneurship activities among the local communities as a means to alleviate poverty (Al-Haj, 2016) and unemployment (Othman and Othman, 2017) by producing job security (Tyszka, Cieślik, Domurat and Macko, 2011) through selfemployment (Chea, 2015). There is also a belief that entrepreneurship is one of the ways to reduce the socio-economic gap among the different ethnicities (Robuan,

*Corresponding Author 
Jaén and Liñán, 2017), and income disparity between urban and rural areas by adopting modern business concepts (Ling, Selvadurai and Hamid, 2017). In line with this, the Ministry of Entrepreneur Development in Malaysia has been continuously encouraging the middle- and lower-income group of people to become competitive entrepreneurs who can tap into the global market (Ministry of Entrepreneur Development, 2019). This initiative has been supported by the Ministry of Education Malaysia by treating entrepreneurship as one of the holistic criteria in leadership skills being channelled to youngsters through formal education (Ministry of Education Malaysia, 2013).

\section{Literature review}

Investment in entrepreneurship education as a path to produce knowledge-based entrepreneurs is expected to contribute a positive return to the nation (Hayter, 2013). In line with this initiative, irrespective of educational background and major, youngsters are expected to become job creators instead of job seekers by undergoing formal entrepreneurship education at the primary, secondary, and tertiary levels in Malaysia (Kamaruddin, Othman, Hassan, Zaki, and Sum, 2017). The entrepreneurial emphasis given to the students through formal education, especially at the tertiary level, has also indirectly spurred the entrepreneurship intention (Kumar and Kurniawan, 2019) towards international students (Joseph, 2017). This is not only due to the content of the entrepreneurship course but due to the university environment (Trivedi, 2017) that creates a strong atmosphere of awareness concerning the entrepreneurship profession as a well-respected career (Ibrahim, Bakar, Asimiran, Mohamed and Zakaria, 2015). However, there is still a belief that there is low understanding concerning entrepreneurship among the youngsters in Malaysia. This is because the current formal education on entrepreneurship is not directly linked to the skills that are expected by the students (Cheng, Chan and Mahmood, 2009). Due to the contradictory beliefs, the involvement of the local community in entrepreneurship is still considered as not at the maximum level. Indirectly, this indicates that there are still some loopholes that should be investigated and the need for continuous improvement on a regular basis.

The combination of passion, self-confidence, physical infrastructure (Noor, Mahmud, Nga and Mail, 2017), and the financial environment (Ahmad and Xavier, 2012) is expected to stimulate entrepreneurship activities. This can be further enhanced through the willingness of the youngsters to learn and explore new technology (Hoque, Awang and Siddiqui, 2017), especially in terms of specific technical knowledge and innovation (Odewale, Hani, Migiro and Adeyeye, 2019) and adapt the knowledge to the concept of entrepreneurship. Entrepreneurship is a very powerful economic driver to develop the innovation, start-up, and job creation of a nation (Osman and Ngah, 2016). The entrepreneurship empowerment that is given to the youngsters is expected to enhance the socio-economic development momentum for the nation (Ogamba, 2018). The strong culture that is built based on entrepreneurial orientation will definitely stimulate the market, which is very important for business performance (Amin, Thurasamy, Aldakhil and Kaswuri, 2016). 
In addition to empowering youngsters, entrepreneurship also empowers women to be more independent. The hidden glass ceiling barrier for women in professional services has encouraged independent and confident women to venture into entrepreneurship (Sharif, 2015). The additional work experiences gained from their former working profession, personality, and soft skills, especially in communication, are very important for building relationships in entrepreneurship (Ismail, Isa, Alam and Ahmad, 2016) as this will open up a bright and stable path for the women to succeed. This is even further supported by the availability of business advice, education, access to capital, and entrepreneurship programmes (Ariffin, Baqutayan, Mahdzir, 2017). In addition, the cumulative skills and experience in entrepreneurship practice will definitely have a positive impact on business performance (Ong, Habidin, Salleh and Fuzi, 2016).

Understanding the attitude of youngsters to be entrepreneurs is very important because attitude is able to influence the entrepreneurial intention (Chea, 2015; Trivedi, 2017). There are also entrepreneurship researchers who believe that attitude towards sustainability and perceived entrepreneurial desirability influence the entrepreneurial intention (Vuorio, Puumalainen and Fellnhofer, 2018), and that the individual's attitude is important to ensure the sustainability of the entrepreneurship (Koe, Omar and Sa'ari, 2015). Further findings also indicate that entrepreneurial learning and entrepreneurial intention are mediated by attitude (Zhang, Wei, Sun and Tung, 2018). In line with similar reasons made by a few entrepreneurship scholars, the majority of the modern education system has been trying to develop the entrepreneurship attitude within students through formal teaching and learning (Hörnqvist and Leffler, 2014). It is expected that a formal entrepreneurship course will create a positive attitude towards entrepreneurship (Ustav and Venesaar, 2018; Aminin and Kumar, 2020) since the intention to become an entrepreneur is influenced by the individual's attitude (Ambad and Damit, 2016) and supported by education (Gelaidan and Abdullateef, 2017).

\section{Research Method}

This research was based on cross-sectional quantitative research where the data were collected from students at the Multimedia University, Cyberjaya, Selangor, Malaysia, as respondents. Cyberjaya is one of the well-known intelligent cities within Selangor state, and the Multimedia University was the first tertiary institution to be built in Cyberjaya. At 6,495,4000, Selangor has the highest population density of all the states in Malaysia; the overall population in Malaysia is 32.5 million (Department of Statistics Malaysia, 2018). Selangor is also known to be the most developed state since the location surrounds the capital city of Kuala Lumpur. Due to high exposure to the contemporary socio-economic environment, the respondents from this area are expected to be very open-minded. To ease the data collection, the survey questionnaire was distributed to the students in the university library. A brief explanation was given to the respondents to ensure that the questionnaire could be easily understood. The feedback from the respondents was manually screened to avoid major missing data. None of the respondents was forced to participate to ensure the sincerity of the feedback. In addition, a token of appreciation was given to the respondents as a form of encouragement. 
There are six items to represent each of the attitude and intention constructs. A Likert scale was used for the respondents to rate psychological feedback (Xu and Leung, 2018). The Likert scale was introduced by Rensis Likert (1932). Although many researchers have used a five-point Likert scale (Jamieson, 2004), Symonds (1924) found that maximum reliability can be achieved through the use of a sevenpoint scale. It is also believed that increasing the number of points above seven will not make research on human perception more precise (Miller, 1956). In addition to the statistical reliability, a scale with an odd number of points provides flexibility for the respondents to provide neutral feedback instead of being forced to provide either a positive or negative opinion (Croasmun and Ostrom, 2011). The sevenpoint Likert scale in this research is 1) strongly disagree, 2) disagree, 3) somewhat disagree, 4) neutral, 5) somewhat agree, 6) agree, and 7) strongly agree. The items for both the attitude and intention constructs is set as in the questionnaire; as shown in Table 1 and Table 2.

Table 1: Attitude Items

\begin{tabular}{|c|c|}
\hline Code & Item \\
\hline AT1 & My ambition is to be an entrepreneur \\
\hline AT2 & Being an entrepreneur will secure my future life \\
\hline AT3 & $\begin{array}{l}\text { Being an entrepreneur will give me an opportunity to } \\
\text { challenge myself }\end{array}$ \\
\hline AT4 & Being an entrepreneur will empower my future life \\
\hline AT5 & Being an entrepreneur will show my real personality \\
\hline AT6 & I have always been interested in entrepreneurship \\
\hline \multicolumn{2}{|r|}{ Table 2: Intention Items } \\
\hline Code & Item \\
\hline IN1 & I am preparing myself to become an entrepreneur \\
\hline IN2 & I will work hard to become an entrepreneur \\
\hline IN3 & I intend to become an entrepreneur to challenge myself \\
\hline IN4 & I am looking for an opportunity to be an entrepreneur \\
\hline IN5 & Being an entrepreneur is my priority after I graduate \\
\hline IN6 & The best investment in life is to be an entrepreneur \\
\hline
\end{tabular}

Overall, 425 data were used for analysis. The collected data were analyzed using the descriptive analysis to discover the background to the attitude and intention feedback based on the Likert scale through the median, mode (McLeod, 2008), and mean. Further, the correlation relationship between the attitude and intention constructs was analyzed to determine how far the attitude will influence the intention of the youngsters to venture into entrepreneurship.

\section{Result and Discussion}

\subsection{Respondents' Background}

All the data were collected from students in Multimedia University, Cyberjaya, Selangor. The majoring education background of the students is categorized into business management, computing and information technology, engineering, creative multimedia, communication, and others. Overall, 165 of the respondents $(38.8 \%)$ are studying business management, 109 of the respondents $(25.6 \%)$ are 
studying computing and information technology, $88(20.7 \%)$ are studying engineering, $54(12.7 \%)$ are studying creative multimedia, and only 7 of the respondents $(1.6 \%)$ are studying communication. There are also 2 respondents $(0.5 \%)$ who are studying uncommon programmes. The background showing the education major of the respondents is, as shown in Table 3.

Table 3: Education Background

\begin{tabular}{lll}
\hline Education Background & Frequency & Percentage \\
\hline Business management & 165 & $38.8 \%$ \\
Computing and information technology & 109 & $25.6 \%$ \\
Engineering & 88 & $20.7 \%$ \\
Creative multimedia & 54 & $12.7 \%$ \\
Communication & 7 & $1.6 \%$ \\
Others & 2 & $0.5 \%$ \\
Total & $\mathbf{4 2 5}$ & $\mathbf{1 0 0 \%}$ \\
\hline
\end{tabular}

The total duration for studying at the tertiary education level depends on the programme. Most degree programmes take four to five years to graduate while diploma programmes normally take two to three years to graduate on a full-time basis, depending on the major. Master programmes normally take 1 to 2 years, and doctorate programmes normally take 3 to 5 years. The overall duration will double if the students are studying on a part-time basis. Due to the culture, the majority of students manage to graduate from tertiary education level according to the proposed length. Only a few students are unable to meet the expected graduation target on time.

Overall, 150 of the respondents $(35.3 \%)$ are from the first year, 124 respondents $(29.2 \%)$ are from the second year, $89(20.9 \%)$ are from the third year, $33(7.8 \%)$ are from the fourth year, $14(3.3 \%)$ are from the fifth year, and 15 respondents (3.5\%) do not belong to any of the officials proposed academic years. The number of respondents reduces according to the year of study because the data were collected from the students studying in the library on the university campus, and the university gives priority to junior students to stay on campus. The on-campus accommodation is only given to senior students if space is available. Hence, the majority of students who are studying in the library are juniors, and the number reduces according to the year of study. The year of study background for the respondents is summarized in Table 4.

Table 4: Year of Study

\begin{tabular}{lll}
\hline Year of Study & Frequency & Percentage \\
\hline First year & 150 & $35.3 \%$ \\
Second year & 124 & $29.2 \%$ \\
Third year & 89 & $20.9 \%$ \\
Fourth year & 33 & $7.8 \%$ \\
Fifth year & 14 & $3.3 \%$ \\
Others & 15 & $3.5 \%$ \\
Total & $\mathbf{4 2 5}$ & $\mathbf{1 0 0 \%}$ \\
\hline
\end{tabular}

Of the 425 students who participated in the survey questionnaire, 250 are male respondents $(58.8 \%)$, and 175 are female respondents $(41.2 \%)$. The percentage of 
respondents from both genders reflects the percentage breakdown of male and female students at the university; as shown in Table 5.

Table 5: Gender

\begin{tabular}{lll}
\hline Gender & Frequency & Percentage \\
\hline Male & 250 & $58.8 \%$ \\
Female & 175 & $41.2 \%$ \\
Total & $\mathbf{4 2 5}$ & $\mathbf{1 0 0 \%}$ \\
\hline
\end{tabular}

\subsection{Analyses of Constructs}

The findings for the attitude construct show that the highest number of respondents for AT1, AT2, and AT6 is 'neutral' with 138 (32.5\%), $124(29.2 \%)$, and 130 $(30.6 \%)$ respondents, while the lowest number of respondents for the three items is 'strongly disagree' with $25(5.9 \%), 12(2.8 \%)$, and $25(5.9 \%)$ respondents, respectively. For AT3, the highest number of respondents is 'agree' with 128 respondents $(30.1 \%)$, while the lowest number of respondents is 'disagree' with 8 respondents $(1.9 \%)$. The highest number of respondents for AT4 is 'somewhat agree' with 122 respondents $(28.7 \%)$ while the lowest number of respondents is 'strongly disagree' and 'disagree' with 9 respondents $(2.1 \%)$ for each. For AT5, the highest number of respondents is 'neutral' with 137 respondents $(32.2 \%)$ while the lowest number of respondents is similar to AT4, which are 'strongly disagree' and 'disagree' with 16 respondents $(3.8 \%)$ for each. The pattern for the highest number of respondents is between 'neutral' and 'agree'. While the pattern for the lowest number of respondents is between 'strongly disagree' and 'disagree'.

The median for each item is the middle value between the upper half and lower half of the total number of respondents, while the mode is the highest number of respondents that are given for each item. The construct analyses for attitude in this research found that the overall range for the median and mode is between 4 and 6 . This proves that the majority of the respondents have a positive attitude towards entrepreneurship since the range for attitude is between being 'neutral' and 'agree'. For analysis of the median, AT3 has a median of 6. AT2, AT4, and AT5 have a median of 5. In comparison, AT1 and AT6 have a median of 4. For the mode analysis, AT3 has a mode of 6 , and AT4 has a mode of 5. All the other items for AT1, AT2, AT5, and AT6 have a mode of 4 . The mean, which is the average point of the given response for AT1, AT2, AT3, AT4, AT5, and AT6 is 4.4071, 4.5576, $5.3482,4.9859,4.6400$ and 4.4541 , respectively. Details of the findings for the attitude construct are shown in Table 6.

Table 6: Attitude

\begin{tabular}{|c|c|c|c|c|c|c|c|c|}
\hline \multicolumn{2}{|c|}{ Scale } & Feedback & AT1 & AT2 & AT3 & AT4 & AT5 & AT6 \\
\hline \multirow{2}{*}{1} & Strongly & Frequency & 25 & 12 & 10 & 9 & 16 & 25 \\
\hline & disagree & Percentage & $5.9 \%$ & $2.8 \%$ & $2.4 \%$ & $2.1 \%$ & $3.8 \%$ & $5.9 \%$ \\
\hline \multirow[t]{2}{*}{2} & \multirow{2}{*}{ Disagree } & Frequency & 26 & 23 & 8 & 9 & 16 & 29 \\
\hline & & Percentage & $6.1 \%$ & $5.4 \%$ & $1.9 \%$ & $2.1 \%$ & $3.8 \%$ & $6.8 \%$ \\
\hline \multirow{2}{*}{3} & Somewhat & Frequency & 38 & 45 & 12 & 15 & 40 & 38 \\
\hline & disagree & Percentage & $8.9 \%$ & $10.6 \%$ & $2.8 \%$ & $3.5 \%$ & $9.4 \%$ & $8.9 \%$ \\
\hline \multirow{2}{*}{4} & & Frequency & 138 & 124 & 68 & 116 & 137 & 130 \\
\hline & Neutral & Percentage & $32.5 \%$ & $29.2 \%$ & $16.0 \%$ & $27.3 \%$ & $32.2 \%$ & $30.6 \%$ \\
\hline \multirow{2}{*}{5} & Somewhat & Frequency & 98 & 115 & 111 & 122 & 91 & 95 \\
\hline & agree & Percentage & $23.1 \%$ & $27.1 \%$ & $26.1 \%$ & $28.7 \%$ & $21.4 \%$ & $22.4 \%$ \\
\hline
\end{tabular}




\begin{tabular}{|c|c|c|c|c|c|c|c|c|}
\hline \multirow{2}{*}{6} & \multirow{2}{*}{ Agree } & Frequency & 60 & 69 & 128 & 105 & 74 & 55 \\
\hline & & Percentage & $14.1 \%$ & $16.2 \%$ & $30.1 \%$ & $24.7 \%$ & $17.4 \%$ & $12.9 \%$ \\
\hline \multirow{2}{*}{7} & Strongly & Frequency & 40 & 37 & 88 & 49 & 51 & 53 \\
\hline & agree & Percentage & $9.4 \%$ & $8.7 \%$ & $20.7 \%$ & $11.5 \%$ & $12.0 \%$ & $12.5 \%$ \\
\hline \multirow{2}{*}{\multicolumn{2}{|c|}{ Total }} & Frequency & 425 & 425 & 425 & 425 & 425 & 425 \\
\hline & & Percentage & $100 \%$ & $100 \%$ & $100 \%$ & $100 \%$ & $100 \%$ & $100 \%$ \\
\hline \multicolumn{3}{|c|}{ Median } & 4 & 5 & 6 & 5 & 5 & 4 \\
\hline \multicolumn{3}{|c|}{ Mode } & 4 & 4 & 6 & 5 & 4 & 4 \\
\hline \multicolumn{3}{|c|}{ Mean } & 4.4071 & 4.5576 & 5.3482 & 4.9859 & 4.6400 & 4.4541 \\
\hline
\end{tabular}

For the intention construct, the highest number of respondents for IN1 is 'neutral' with 130 respondents $(30.6 \%)$, while the lowest number of respondents is 'strongly agree' with 28 respondents $(6.6 \%)$. The highest number of respondents for IN2 is also 'neutral' with 129 respondents $(30.4 \%)$, while the lowest number of respondents is 'disagree' with 25 respondents (5.9\%). The majority of the 117 respondents $(27.5 \%)$ perceived IN3 as 'neutral' while the minority perceived the item as 'strongly disagree' and 'disagree', which is represented by 27 respondents (6.4\%) for each. The response for item IN4 shows that the majority of the 105 respondents $(24.7 \%)$ perceived the item as 'somewhat agree', while only 26 of the respondents $(6.1 \%)$ perceived the item as 'strongly disagree'. For IN5, 136 of the respondents $(32.0 \%)$ perceived the item as 'neutral' and only 38 of the respondents $(8.9 \%)$ perceived the item as 'strongly agree'. Finally, for item IN6, 113 of the respondents $(26.6 \%)$ perceived the item as 'neutral', while only 31 of the respondents $(7.3 \%)$ perceived the item as 'disagree'. The pattern for the highest number of respondents is between 'neutral' and 'somewhat agree'. While the pattern for the lowest number of respondents is scattered along the seven-point Likert scale.

The analysis of the intention construct in this research shows that the overall range for the median, mode, and mean is between 4 and 5. This proves that the majority of the respondents have a positive intention towards being an entrepreneur since the range for the intention is between being 'neutral' and 'somewhat agree'. The item for IN4 has a median and mode of 5. While the other items, which are IN1, IN2, IN3, IN5, and IN6, have a median and mode of 4. The mean, which is the average point of the given response for IN1, IN2, IN3, IN4, IN5, and IN6, are $3.9788,4.4141,4.4494,4.5859,4.0329$, and 4.2894, respectively. Details of the findings for the intention construct are shown in Table 7.

Table 7: Intention

\begin{tabular}{rllllllll}
\hline Scale & Feedback & IN1 & IN2 & IN3 & IN4 & IN5 & IN6 \\
\hline \multirow{2}{*}{1} & Strongly & Frequency & 35 & 32 & 27 & 26 & 41 & 34 \\
& disagree & Percentage & $8.2 \%$ & $7.5 \%$ & $6.4 \%$ & $6.1 \%$ & $9.6 \%$ & $8 \%$ \\
2 & Disagree & Frequency & 46 & 25 & 27 & 33 & 40 & 31 \\
& & Percentage & $10.8 \%$ & $5.9 \%$ & $6.4 \%$ & $7.8 \%$ & $9.4 \%$ & $7.3 \%$ \\
\multirow{2}{*}{3} & Somewhat & Frequency & 64 & 35 & 42 & 27 & 57 & 51 \\
& disagree & Percentage & $15.1 \%$ & $8.2 \%$ & $9.9 \%$ & $6.4 \%$ & $13.4 \%$ & $12.0 \%$ \\
\multirow{2}{*}{4} & Neutral & Frequency & 130 & 129 & 117 & 104 & 136 & 113 \\
& & Percentage & $30.6 \%$ & $30.4 \%$ & $27.5 \%$ & $24.5 \%$ & $32.0 \%$ & $26.6 \%$ \\
\multirow{2}{*}{5} & Somewhat & Frequency & 76 & 97 & 102 & 105 & 66 & 99 \\
& agree & Percentage & $17.9 \%$ & $22.8 \%$ & $24.0 \%$ & $24.7 \%$ & $15.5 \%$ & $23.3 \%$ \\
\hline
\end{tabular}




\begin{tabular}{|c|c|c|c|c|c|c|c|c|}
\hline \multirow{2}{*}{6} & \multirow{2}{*}{ Agree } & Frequency & 46 & 61 & 64 & 75 & 47 & 52 \\
\hline & & Percentage & $10.8 \%$ & $14.4 \%$ & $15.1 \%$ & $17.6 \%$ & $11.1 \%$ & $12.2 \%$ \\
\hline \multirow{2}{*}{7} & Strongly & Frequency & 28 & 46 & 46 & 55 & 38 & 45 \\
\hline & agree & Percentage & $6.6 \%$ & $10.8 \%$ & $10.8 \%$ & $12.9 \%$ & $8.9 \%$ & $10.6 \%$ \\
\hline \multirow{2}{*}{\multicolumn{2}{|c|}{ Total }} & Frequency & 425 & 425 & 425 & 425 & 425 & 425 \\
\hline & & Percentage & $100 \%$ & $100 \%$ & $100 \%$ & $100 \%$ & $100 \%$ & $100 \%$ \\
\hline \multicolumn{3}{|c|}{ Median } & 4 & 4 & 4 & 5 & 4 & 4 \\
\hline \multicolumn{3}{|c|}{ Mode } & 4 & 4 & 4 & 5 & 4 & 4 \\
\hline \multicolumn{3}{|c|}{ Mean } & 3.9788 & 4.4141 & 4.4494 & 4.5859 & 4.0329 & 4.2894 \\
\hline
\end{tabular}

\subsection{Correlation Analysis}

Further correlation analysis was undertaken to discover the relationship between attitude and intention. Based on the findings, there is a significantly positive relationship between the attitude and the intention of the youngsters towards being an entrepreneur $(\rho$-value $<0.05)$. Those youngsters who have a positive attitude towards entrepreneurship also have a positive intention to become an entrepreneur. According to Evans (1996), the Pearson correlation relationship can be categorized as very weak if the r-value is below 0.19 , weak if the $r$-value is between 0.20 and 0.39 , moderate if the r-value is between 0.40 and 0.59 , strong if the r-value is between 0.60 and 0.79 , and very strong if the r-value is above 0.80 . Hence, the correlation relationship for the research findings is considered as very strong since the r-value is 0.798 . The correlation findings for entrepreneurship attitude and intention are shown in Table 8.

Table 8: Correlation

\begin{tabular}{|c|c|}
\hline Correlation & Result \\
\hline $\begin{array}{l}\text { Pearson correlation (r-value) } \\
\rho \text {-value }\end{array}$ & $\begin{array}{l}0.798 \\
0.0001\end{array}$ \\
\hline
\end{tabular}

\section{Conclusion and Implications}

This research has proven that the majority of youngsters have a positive attitude and intention to become entrepreneurs. Further analysis also shows that there is a significant positive relationship between attitude and intention. The findings from this research are similar to the findings made by other researchers (Ambad and Damit, 2016; Chea, 2015; Trivedi, 2017). However, this research only focuses on the feedback based on the attitude and intention constructs. It would be worthwhile extending the research by determining how to shape a positive attitude and intention. For example, further research can be done by looking at the elements that build-up the positive attitude and intention among the youngsters.

The efforts to embed entrepreneurship courses through formal education at the primary, secondary and tertiary levels seem worthwhile. Nevertheless, a further boost can be made by giving the tertiary level students an opportunity to practice their entrepreneurship skills by building market prototypes as a final year project to sharpen the hidden entrepreneurship talents. Such encouragement of formal entrepreneurship will definitely enhance the existing creativity with embedded skills and knowledge learned through practical hands-on opportunities. This can be suggested as an elective course for those students who have a high intention to become entrepreneurs. 
The relationship between attitude and intention can also be extended by adding more constructs into the existing relationship. This research only focuses on students from Multimedia University, which is within the state of Selangor. Further findings can be derived from research conducted at the primary or secondary school levels and in other states. Human behaviour continuously changes due to age and the environment. It would be interesting to do research based on different age groups. Furthermore, each state in Malaysia is unique in terms of culture, geographical location, and the environment. Diverse entrepreneurship start-ups can be encouraged that reflect the strength of the states.

The momentum for entrepreneurship will always be evergreen, and, nowadays, the availability of a virtual market gives full empowerment for the youngsters to tap into the global market straight away without the need for the tremendous effort of struggling with the local market as a warm-up. Due to the revolution in entrepreneurship, nowadays, face-to-face communication skills have been diverted into virtual communication skills to attract customers on a virtual basis. Nevertheless, the traditional entrepreneurship methods are hardly obsolete since society will always be looking for diverse channels. The availability of information technology and communication offers the youngsters an additional entrepreneurship path by being virtual. In line with this, the research on entrepreneurship should always be expanding to cover various angles.

Exposure to entrepreneurship should not just focus on students. The entrepreneurship programme should also be conducted for students who have dropped out, housewives, prisoners, and anybody who is interested in learning and being guided on how to start a new business. Although many of the available entrepreneurship programmes have been conducted by the government, the private sector, and non-government organizations, not everyone knows about the entrepreneurship support that is available. Normally, only those who are extremely aggressive will find a way to grasp the opportunity while others prefer to wait for the opportunity to come to their doorstep. Introducing entrepreneurship through formal education is expected to overcome this issue. The entrepreneurship effort by society is expected to make the socio-economics more stable. As a developing country that is aiming to achieve developed status, society should be more independent and being an entrepreneur is one of the ways to survive the modern industrial revolution.

The entrepreneurship momentum that was initiated for the youngsters seems worthwhile since the majority of the youngsters have a positive attitude towards entrepreneurship. The youngsters also have a positive tendency towards the intention of venturing into entrepreneurship. Further findings have proven that a positive attitude will lead to a positive intention to be an entrepreneur. Overall, the findings provide a good indicator that the majority of the youngsters perceived that being an entrepreneur is a very well-respected profession. It is highly expected that socio-economic development will be further strengthened by continuous strong support and motivation through formal entrepreneurship education and informal entrepreneurship courses.

\section{Acknowledgement}

Deepest appreciation is given to the Minister of Higher Education Malaysia for funding this research project through the Fundamental Research Grant Scheme 
(FRGS) (Project ID: FRGS/1/2018/SS03/MMU/03/2) and the Multimedia University, Malaysia, for the continuous support and motivation.

\section{References}

Ahmad, S. Z. and Xavier, S. R. (2012). Entrepreneurial environments and growth: Evidence from Malaysia GEM data, Journal of Chinese Entrepreneurship, Vol. 4, No. 1, pp. 50-69.

Al-Haj, N. H. Y. Y. (2016). Malaysia: Entrepreneurship and sustainability in Malaysia: business solutions for poverty alleviation, Entrepreneurship and Sustainability, Routledge.

Ambad, S. N. A. and Damit, D. H. D. A. (2016). Determinants of entrepreneurial intention among undergraduate students in Malaysia, Economics and Finance, Vol. 37, pp. 108-114.

Amin, M., Thurasamy, R., Aldakhil, A. M., and Kaswuri, A. H. (2016). The effect of market orientation as a mediating variable in the relationship between entrepreneurial orientation and SMEs performance, Nankai Business Review International, Vol. 7, No. 1, pp. 39-59.

Aminin, T.A. and Kumar, S. (2020). Antecedents and Consequences of Entrepreneurial Quality among Graduate Entrepreneurs in Jakarta. CV Rasi Terbit.

Ariffin, A. S., Baqutayan, S. M. S. and Mahdzir, A. M. (2018). Enhancing women entrepreneurship development framework: Policy and institution gap and challenges in the case of Malaysia, Journal of Science, Technology and Innovation Policy, Vol. 3, No. 2, pp. 1-12.

Chea, C. C. (2015). Entrepreneurship intention in an open and distance learning (ODL) institution in Malaysia, MOJEM: Malaysian Online Journal of Educational Management, Vol. 3, No. 3, pp. 31-33.

Cheng, M. Y., Chan, W. S. and Mahmood, A. (2009). The effectiveness of entrepreneurship education in Malaysia, Education + Training, Vol. 51, No. 7, pp. 555-566.

Croasmun, J. T. and Ostrom, L. (2011). Using Likert-type Scales in the Social Sciences, Journal of Adult Education, Vol. 40, No. 1, pp. 19-22.

Department of Statistics Malaysia (2018). Demographic Statistics Third Quarter (Q3) 2018, Malaysia.

Evans, J. D. (1996). Straightforward statistics for the behavioral sciences, Pacific Grove, CA: Brooks/Cole Publishing.

Ferreira, N. M. (2018). What is entrepreneurship? Entrepreneur definition and meaning.

Gelaidan, H. M. and Abdullateef, A. O. (2017). Entrepreneurial intentions of business students in Malaysia: The role of self-confidence, educational and relation support, Journal of Small Business and Enterprise Development, Vol. 24, No. 1, pp. 54-67.

Hayter, C. S. (2013). Conceptualizing knowledge-based entrepreneurship networks: Perspectives from the literature, Small Business Economics, Vol. 41, No. 4, pp. 899-911.

Hoque, A. S. M. M., Awang, Z. and Siddiqui, B. A. (2017). Technopreneurial intention among university students of business courses in Malaysia: A 
structural equation modelling, International Journal of Entrepreneurship and Small and Medium Enterprise, Vol. 4, pp. 1-16.

Hörnqvist, M. L. and Leffler, E. (2014). Fostering an entrepreneurial attitudechallenging in principal leadership, Education + Training, Vol. 56, No. 6, pp. 551-561.

Ibrahim, W. N. A., Bakar, A. R., Asimiran, S., Mohamed, S. and Zakaria, N. S. (2015). Impact of Entrepreneurship Education on the Entrepreneurial Intentions of Students in Technical and Vocational Education and Training Institutions (TVET) in Malaysia, International Education Studies, Vol. 8, No. 12, pp. 141-156.

Ismail, M. D., Isa, A. M., Alam, S. S., and Ahmad, M. (2016). Market orientation, entrepreneurship orientation, relationship commitment and communication among SME exporters in Malaysia, Geografia-Malaysian Journal of Society and Space, Vol. 12, No. 1, pp. 19-28.

Jamieson, S. (2004). Likert scales: How to (ab)use them, Medical Education, Vol. 38, No. 12, pp. 1217-1218.

Joseph, I. (2017). Factors influencing international student entrepreneurial intention in Malaysia, American Journal of Industrial and Business Management, Vol. 7, No. 4, pp. 424-428.

Kamaruddin, H., Othman, N., Hassan, R., Zaki, W. M. D. W., and Sum, S. M. (2017). The government's role in the importance of entrepreneurship education amongst university students in Malaysia, In Leadership, Innovation and Entrepreneurship as Driving Forces of the Global Economy, pp. 579-587, Springer.

Kumar, S. and Kurniawan, D. (2019). The Relationship between Entrepreneurial Education, Family Background, Innovativeness, and Entrepreneurial Capabilities Toward Entrepreneurial Intention. The $3^{\text {rd }}$ International Conference on Family Business and Entrepreneurship, pp. 631-642. President University.

Koe, W. L., Omar, R. and Sa'ari, J. R. (2015). Factors influencing propensity to sustainable entrepreneurship of SMEs in Malaysia, Social and Behavioral Sciences, Vol. 172, pp. 570-577.

Likert, R. (1932). A technique for the measurement of attitudes. Archives of Psychology. New York: Columbia University Press.

Ling, C. K., Selvadurai, S. and Hamid, B. A. (2009). Malay youth entrepreneurship in Malaysia: An empirical update, Geografia-Malaysian Journal of Society and Space, Vol. 5, No. 2, pp. 55-67.

McLeod, S. (2008). Likert scale, Simply Psychology.

Miller, G. A. (1956). The magical number seven, plus or minus two: Some limits on our capacity for processing information, Psychological Review, Vol. 63, pp. 81-97.

Ministry of Education Malaysia (2013). Malaysia education blueprint 2013-2025, preschool to post-secondary education.

Ministry of Entrepreneur Development (2019). Vision, mission and function.

Noor, F. F., Mahmud, R., Nga, J. L. H., and Mail, R. (2017). Motivating factors and prospects for rural community involvement in entrepreneurship: Evidence from Mantanani Island, Sabah, Malaysia, International Journal of Social, Behavioral, Educational, Economic, Business and Industrial Engineering, Vol. 11, No. 1, pp. 267-272. 
Odewale, G. T., Hani, S. H. A., Migiro, S. O., and Adeyeye, P. O. (2019). Entrepreneurship education and students' views on self-employment among international postgraduate students in Universiti Utara Malaysia, Journal of Entrepreneurship Education, Vol. 22, No. 1, pp. 1-15.

Ogamba, I. K. (2018). Millennials empowerment: youth entrepreneurship for sustainable development, World Journal of Entrepreneurship, Management and Sustainable Development.

Ong, S. Y. Y., Habidin, N. F., Salleh, M. I., and Fuzi, N. M. (2016). Relationship of entrepreneurship practice and business performance of women entrepreneur in Malaysia, International Journal of Academic Research in Business and Social Sciences, Vol. 6, No. 11, pp. 95-109.

Osman, C. A. and Ngah, R. (2016). Assessing sustainable competitive advantage in relation with intellectual capital, knowledge management and innovativeness in women-owned SMEs in Malaysia, Journal of International Business, Economics and Entrepreneurship, Vol. 1, No. 1, pp. 46-51.

Othman, N. and Othman, S. H. (2017). The perceptions of public university students of entrepreneurship education in Malaysia, International Business Management, Vol. 11, No. 4, pp. 865-873.

Robuan, M. R. S., Jaén, I. and Liñán, F. (2017). 5. Promoting entrepreneurship in an unfavourable setting: A case study of a university programme in Malaysia, The Emergence of Entrepreneurial Behaviour: Intention, Education and Orientation, Edward Elgar Publishing Limited.

Sharif, M. Y. (2015). Glass ceiling, the prime driver of women entrepreneurship in Malaysia: A phenomenological study of women lawyers, Procedia-Social and Behavioral Sciences, Vol. 169, pp. 329-336.

Symonds, P. M. (1924). On the loss of reliability in ratings due to coarseness of the scale, Journal of Experimental Psychology, Vol 7, pp. 456-461.

Trivedi, R. H. (2017). Entrepreneurial-intention constraint model: A comparative analysis among post-graduate management students in India, Singapore and Malaysia, International Entrepreneurship and Management Journal, Vol. 13, No. 4, pp. 1239-1261.

Tyszka, T., Cieślik, J., Domurat, A., and Macko, A. (2011). Motivation, selfefficacy, and risk attitudes among entrepreneurs during transition to a market economy, The Journal of Socio-Economics, Vol. 40, No. 2, pp. 124-131.

Ustav, S. and Venesaar, U. (2018). Bridging metacompetencies and entrepreneurship education, Education + Training, Vol. 60, No. 7/8, pp. 674695.

Vuorio, A. M., Puumalainen, K. and Fellnhofer, K. (2018). Drivers of entrepreneurial intentions in sustainable entrepreneurship, International Journal of Entrepreneurial Behavior and Research, Vol. 24, No. 2, pp. 359381.

Xu, M. L. and Leung, S. O. (2018). Effects of varying numbers of Likert scale points on factor structure of the Rosenberg Self-Esteem Scale, Asian Journal of Social Psychology, Vol. 21, Iss. 3, pp. 119-128.

Zhang, F., Wei, L., Sun, H., and Tung, L. C. (2018). How entrepreneurial learning impacts one's intention towards entrepreneurship: A planned behavior approach, Chinese Management Studies. 